\title{
The Effectiveness of the School Performance, by Using the Total Quality Standards within the Education District of Al-Petra Province, from the Perspective of the Public Schools Principals and Teachers
}

\author{
Ahmad Alobiedat (Corresponding author) \\ Faculty of Education \\ Tafila Technical University \\ P.O. Box 179 Zip code 66110 Jordan \\ Tel: 962-777-271-789 E-mail: alobiedat@yahoo.com
}

Received: May 10, 2010 Accepted: May 26, 2010 doi:10.5539/ies.v4n2p31

\begin{abstract}
This study aimed to detect the level of appreciation by the school principals, teachers and the Education District, for the effectiveness of school performance, within different variables of the study from the perspective of public school principals and teachers of Al-Petra province, for the academic year 2008/2009. The study aimed to answer the two questions: What is the level of the effectiveness of school performance by using the TQS in Al-Petra province public schools as perceived school principals, and teachers? The second question: Are there any significant differences to the level of the effectiveness of school performance by using the TQS as perceived by school principals, and teachers, attributed to variables: gender, educational credentials employment status, and experience?. The results of the study indicated that the implementation of educational technology came in the first place its probably due to the concern the Ministry of Education, also the study indicate that the level of utilizing strategies planning came to a medium degree in the last rank of the six dimensions this may be due to the fact that the practice of school administrators for planning still depends on improvisation sometimes or situational management, while there is significant difference attributable to the gender, it was in favor of males school principals in the area of school learning and school climate, it's probably due to the attention of male school administrators, finely the study indicated that there was no statistically significant difference due to the experience variable in all dimensions.
\end{abstract}

Keywords: The Effectiveness, Total Quality Standards, Public School, Al-Petra province

\section{Introduction}

One of the distinctive characteristics of this era, the accelerating of its events, with the accumulation of enormous amounts of knowledge around us, with diverse forms of conflict which is characterized by a high degree of competition prevail in of our life, whether on the individual level with each other or between institutions in order to achieve higher levels of quality production. At the level of services, it is no longer achieving the objectives in the minimal level, where the efforts of individuals and institutions stand, but achieving the higher degree level by accepting excellent work, with height performance standards to the highest possible ambition, is the ultimate goal which everyone is trying to achieve and hope that aspire to achieve. The excel elements are an indispensable investment in the performance of the all tasks in this era. Management excel includes two aspects: the first aspect is related to the new tasks with confirms of the current task that is consistent with its predecessor, which drive the work force movement towards excellence. The second aspect is the impact of excel on the school accomplishments in various aspects, influenced by the first aspect in the educational domain, which was observed in different branches of leadership where they use theories, methods, and modern concepts. Schools of Education are neither preparing teachers adequately to use the concrete findings of the best research in education, nor are they providing their students with a thoughtful and academically rich background in the fundamentals of what it means to be an outstanding educator. (Steiner \& Rozen, 2003) comments such as these have led to a lowering of status for teachers and, in many cases, unwillingness on the part of young people to enter the profession. This attention has been demonstrated in the areas of the review of structures and organizations of leadership, the educational legislation, and the methods of selecting and training leaders of the staff in the departments of education. Recently Total Quality Management (TQM) and its applications concord a special importance internationally, in the Middle Eastern, or locally. TQM is one of the prevailing patterns and desirable in the current period, that may be described as the third force in the world after the industrial revolution and technological revolution (Manasir, 1994). There was the need to 
classify TQM as an input from the access of organizational development is essential to improve performance, maintaining the survival of continuity organizational, and face the challenges. TQM is a modern management philosophy based on the number of modern directed concepts of management, which is based in the combination between the basic management tools, innovative efforts, and specialized technical skills in order to improve the level of performance and to improve the continuous development (Khatib, 2004). The meaning of Total Quality (TQ) in the educational domain (A set of standards and procedures, through it we can recognize the reality of outcome for the propose of continuous improvement, TQ indicated overall to the specifications and expected features in each of the outcomes of the processes and activities that through it we can accomplish the targeted specifications. In order to achieve quality education, educational leadership should adopt the principles of the TQM, which must be based on the correct sound principles, on one hand, and be able to provide the staff in the education domain with process and concepts they need to achieve the aimed objectives of the educational institutions that would improve and develop the level of performance and productivity in these institutions (Kazman, 2000). Situated within these institutions is the public school of the Ministry of Education in Jordan, where school administrations and their employees play a big role in raising the level of performance and production, which determine the parameters and illustrate the path to reach the desired objectives in the selected time. This authorizes total commitment to implement TQM in educational institutions. To review the mission and goals of these institutions, and their conservation strategy, standards and procedures and school tests evaluation and to identify the needs of students in terms of their needs and desires and desirable quality of education and work to re-train and develop staff skills to update their position and responsibility so they can comprehend the philosophy of TQM and it functions as well as re-improve the content of school curricula and to what extent the content of school curricula is practical with the requirements of modern life and meet the needs of beneficiaries and the local (Maysa, 2009). There are a range of benefits to be derived from implementing quality in education that shows in controlling and develop the school administrative system because of the clarity of performance, defining the responsibilities and increase students performance in all aspects and increase efficiency of education and provide an active working organizational environment in school and team work environment and respond to students, parents, and the local community requirements (Abu Mallouh, 2003). Schools are facing a number of challenges such as the complexity of quality itself, quality assurance systems, and controlling and evaluation at the school where the diverse rapid developments in all dimensions directly affecting the school effective of Total Quality Standard (TQS), where these standards evolve to more advanced levels in quality, which require the school to continue to evolve its expectations to raise production efficiency continuously ( $\mathrm{Al}$ bdullah, 2002). The participation of school management, teachers, students, and members of the local community to be in charge and responsible for education, and control the quality of education, all of this can only be achieved through the existence of policies and clear identified objectives, and the high efficiency administrative systems for the educational institutions, as well as the activation of the monitoring and evaluation system to avoid the falling in feature errors, also a system of effective training and continuing development of professional sustainable for staff in the institutions (Elias, 2007). In order for TQM to achieve the objectives of the education domain, it must have the support from senior management and educational leadership to have the opportunities to implement TQM in educational institutions, and create a productive work climate, as well as create organization culture that is strictly regulated to encourage providing such a climate, the existence of effective management of human assets resources available, and the measurement performance in the light of total quality standards on continuous regular basis (Alfraoi, 2004). The principals who emphasize the process of implementing TQM in education is to: identify the needs and expectations of workers in the educational system from teachers, students, parents, with the emphasis on the improvement and development according to TQS, also the emphasis on teamwork, by focusing on the prevention through supervision to make decisions without prejudice in the light of accurate information. The students academic achievement, considered one of the used indicators to determine the productive efficiency of the school, the argument about these indicators controversial particularly in this time the students dependent on private instruction to improve their abilities, in addition to the traditional pattern of examinations system based on the retrieve information, which led to the controversy over the absenteeism role of the school in the processes of teaching and learning.

\section{Objectives of the Study}

The purpose of this study was aimed to detect the level of appreciation by the school principals, teachers and the Education District, for the effectiveness of school performance, within different variables of the study from the perspective of public school principals and teachers of Al-Petra province, for the academic year 2008/2009.

\section{The Problem of the Study}

Schools provide many educational and learning services for learners, and to the community, but it faces many challenges that prevent them from achieving their objectives, this requires greater efforts to meet these challenges, 
pressures and expectations, to win the confidence of learners, and the community by providing educational facilities necessary for the success of teaching and learning process. From this idea the study came to identify the effectiveness of the school performance, by using the TQS within the Education District of Al-Petra province, from the perspective of public schools principals and teachers.

\section{The Importance of the Study}

The researcher hopes that this study will serve public schools principals and teachers to identify the efficiency of the school performance, by using the TQS. It also serves the educational administrations to make decisions to identify the efficiency of the school performance, by using the TQS through teacher training programs, there for the study hoped to involve in the following:

To identify the effectiveness of the school performance, by using the TQS within the Education District of Al-Petra province, from the perspective of the public schools principals and teachers for the school efficiency in the different variables of the study.

Provide feedback to teachers about the reality of their performance and identify the strengths and the weaknesses on one hand, and on the other hand, motivate them to progress towards success in their knowledge of the strengths and weaknesses in their performance.

Describe to the decision-makers the constraints that limit the effectiveness of the school's performance by using the standards of total quality.

\section{The Limits of the Study}

This study is limited to the school principals, teachers in the Education District, of Al-Petra province, according to data collected from the Education District, from the perspective of school principals and teachers for the academic year 2008/2009.

\section{The Research Question of the Study}

\subsection{The First Question:}

What is the level of the effectiveness of school performance by using the TQS in Al-Petra province public schools as perceived school principals, and teachers?

\subsection{The Second Question:}

Are there any significant differences to the level of the effectiveness of school performance by using the TQS in Al-Petra province public schools as perceived by school principals, and teachers, attributed to variables: gender, educational credentials employment status, and experience?

\section{Literature Review}

For the purposes of this study, school and teacher effectiveness is defined as demonstrating contributions to growth in student life learning. Most of school teachers accomplish other things, including motivating and engaging students acquiring new knowledge and skills, and collaborating with colleagues, but those accomplishments best serve their purpose when they lead teachers to improve student achievement, this mean student learning can be measured in many ways, including but not limited to gains made on standardized tests, improvement on periodic classroom assessments, and performance on end-of-course exams. Regardless of the assessment instrument, teacher effectiveness is demonstrated when student learning improves, and on this point educators and policymakers agree (Darling-Hammond 2007; Gordon etl. 2006). Furthermore, there is agreement that teaching and learning in school progresses toward the goal of graduation with the knowledge and skills needed to succeed in college, work, and as a citizen (Corbett and Huebner 2008). Therefore, the definition of school and teacher effectiveness must focus on growth in student learning that ensures students are successful after graduated from school (Alliance for Excellent Education, 2007). Defining school and teacher effectiveness in terms of student outcomes, such as enhance learning and college or work readiness, frees educators and policymakers to focus on which teachers are getting results and why. When data on student achievement is available, that data creates less need to rely on proxies for teacher effectiveness. For years, educators and policymakers have measured and rewarded teacher quality based on qualifications such as having achieved years of experience, certification status, or advanced degrees, and teachers are generally rewarded based on those criteria. Qualifications serve as quality controls and can sometimes predict student achievement. Nevertheless, qualifications are approximations of effectiveness, rather than direct measures of student learning (Clotfelter et al. 2007; Goldhaber \& Brewer 2000; Goldhaber 2006; Kane \& Staiger 2006; Hanushek et al. 2005; Jepsen \& Rivkin 2002). Research is clear that what a teacher does in the classroom is a far greater predictor of student success than anything else, and students who consistently get effective teachers benefit exponentially (Gordon et al. 2006). Researchers in State of Tennessee have found that students given the most 
effective teachers for three years in a row made over twice the gains of comparable students assigned to the least effective teachers (Sanders and Rivers 1996). Researchers have even found that effective teachers have such a significant impact on a student's ability to learn that teaching can offset learning challenges such as low income levels and achievement gaps (Rivkin et al. 2002; Clotfelter et al. 2007). By showing the magnitude of difference in student outcomes as a result of teaching, such research underscores that effectiveness, more than any other indicator of teacher quality, is the area in which policymakers and educators must focus their attention in order to improve student achievement. The school effectiveness research has been a double-edged sword. As Reynolds has argued, the school effectiveness research has had the positive effect of 'helping to destroy the belief that schools can do nothing to change the society around them and the myth that the influence of the family is so strong on children's development that they are unable to be affected by school' (Reynolds, 1995, p. 2), but he also argues that it has had the negative effect of 'creating the widespread, popular view that schools do not just make a difference, but that they make all the difference' (Reynolds, 1995, p.2). The schools effectiveness depends on the understanding by the school leadership principal and teachers of the attitudes, expectations, and behaviors of the students in various learning situations. Students must also be motivated to satisfy family expectations of them. This also means that school leadership principal and teachers must understand the needs and expectations of students. Thus, the school leadership principal and teachers should lead in ways both acceptable and encouraging for students to strive for school and personal goals and objectives. Teacher education is currently facing a number of tensions as pressures have come from many quarters in the last decade, with perhaps the most intense focus being on the issue of teacher quality. This call for an improvement in the quality of teachers is welcomed by many, but there are inherent dangers too. Cochran-Smith (2004a, p. 3) writes: The Standards and Accountability movement, which started in schools more than a decade ago, has now moved to the training of teachers as the next step in the process. It has been argued that there are a number of factors that have led to the increasing surveillance of teacher education (Roth, 1996, $\mathrm{p}$. 242 cited in Tellez, 2003) Unlike most other reforms in education, in curriculum, in pedagogy and in areas of student welfare and support, that are mostly driven by teachers and administrators seeking to improve what they do on a day to day basis, the standards and accountability movement has been driven by people outside of education, based mostly on the idea that we can no longer trust educators to do what is right.

\section{Terminology Study}

\subsection{What is 'School Effectiveness'?}

By definition, a school is called 'effective' when it achieves what it sets out to achieve. In other words, a school is effective when its processes result in observable (not always quantifiable) positive outcomes in its student population consistently over a period of time (Reynolds 1985). This implies that the effectiveness of a school is dependent more on its' processes' and gauged by its 'outcomes' than on its 'intake'. 'Intake', it is borne out by research, plays only a marginal role in school effectiveness (Charlton et al. 1989). It is to be acknowledged that schools do show considerable variation in terms of student attendance, behaviour, curricular and co-curricular performance, social and civic values, moral character, attitude to life, inter-personal skills and so on. Studies have shown that the main source of this variation does not lie in the formidable stature of the school buildings, school resources, or other infrastructure. These, it is observed, remain as mere cosmetic features that can impress the students but not affect any decisive and lasting influence on them.

\subsection{How to Measure Effectiveness?}

The significant question now is what after all, makes a school different and effective? Are schools the way they are, because of its students, or vice versa? As already mentioned, research shows that it is the 'school processes' rather than the 'intake' that makes a school what it is or what it turns out to be. The cumulative effect of the actual 'school processes' is more significant and contributory than the individual factors mentioned earlier, by themselves. These factors, not in isolation, but in combination with many other crucial factors create the 'ethos' or 'climate' of a school. These determine the school processes, which in turn determine the school outcomes. However, though there are mutual influences, the school processes and the school outcomes very unambiguously indicate a greater effect of schools on students than students on schools. To put in other words, it is the student who is groomed by the school and not the school by the student. The 'effectiveness of a school' depends presumably on the 'school climate' developed and nurtured over a period of time, and consolidated through years of perseverance and hard work.

\subsection{School Climate}

School life has a perennial impact on the child. Those who make decisions in relation to education are often concerned only with the form of education, not its substance. Not enough thought is bestowed on the need to create the right climate in our schools. 
We must know for a fact that a child's learning and behaviour depend largely on the kind of school climate he/she lives in. Researchers have pointed out "a significant difference in student achievement between schools with a good school climate and those with a poor school climate." (Bulach, Malone \& Castleman, 1995). We, therefore, must identify the factors that enable a healthy school climate, and create them in every school, because that is the very quintessence of a good school. Every school has its own character, and a distinct identity of its own. This is the sum total of all the values and norms and the adherence to it, which have been internalised by all or most of the people associated with a school, which form a part of everyone's psyche. When people refer to the 'traditions' of a school, they are actually speaking about these deeply embedded characteristics of the school. This becomes the 'school climate'. These are all different ways of describing the 'quality of life' that is experienced and lived by all the participants in the school life; this in turn is recognised by the parents and the community that surround the school.

\section{Methodology}

\subsection{The Population and Sample of the Study:}

The study population consist of all public schools principals, teachers and the Education District of Al-Petra province their total counts was 49 male and female principal, 217 male and female teachers the researcher randomly selected 30\% group of male and female teachers for the academic year 2008/2009.

\subsection{Study Instrument:}

To accomplish the objectives, the researcher developed instrument by using a likert scale, consisted of two dimensions; the first dimension consist the demographic information, and second consist of 53 items distributed on six dimensions.

\subsection{Instrument Validity:}

To verify the validity of the instrument in terms of objectivity, language, and the number of items, the instrument was submitted to panel of referees from faculties of education colleges in Jordanian universities to revise it, and report their remarks about the items a modification has been made according to the advised by the arbitrators.

\subsection{Instrument Reliability:}

To verify the reliability of the instrument the researcher used the internal consistency by using Cronbach Alpha, the reliability of the scale was 0,84 , and the domains were between ( 0.86 to 0.93 ) which is fit suitable for this study.

\section{Results and Discussion}

\subsection{The First Question}

What is the level of the efficiency of school performance by using the TQS in Al-Petra province public schools as perceived school principals, and teachers?

To answer this question, the means, and standard deviations, for the school principal, and school teacher as in shown in table 1 below.

The result interpretation from table 1 above, the researcher depended on cut-of-scores as follow: when the mean between 3.68 and 5 the efficiency of school performance is high, if the mean between 2.34 and 3.67 the efficiency of school performance is medium, when the mean between 1 and 2.33 the efficiency of school performance is considered low, the result from table 1 above indicate the efficiency of school performance distribution for both school principle and school teacher are in accordance they scored, high in the domains of strategic planning exams \& testing, learning climate, and educational technology, while the result indicate medium, in the domains of school leadership, school learning, and strategic planning.

\subsection{The Second Question}

Are there any significant differences to the level of the efficiency of school performance by using the TQS in Al-Petra province public schools as perceived school principals, and teachers, attributed to variables: gender, educational credentials employment status, and experience?

In order to answer this question, the mean and the standard deviations was computed for the six domains according to the gender, then in that case to detect the statistical significant differences between means the independent sample $\mathrm{T}$ test was used, and the results as shown in table 2 below.

It's clear from the table 2 above the result shows that there are no significance differences, due to the gender variable in all domains except in the domains, school learning, and learning climate, it was in favor of male in the two domains. 
The means and standard deviation for the six domains was computed, to answer the part that related to the educational credentials of school principle and school teacher, therefore to detect the statistical significant differences between means the independent sample $\mathrm{T}$ test show the results in table 3 below.

The result from table 3 above shows that there is a significant difference, due to the educational credentials, in all domains except in the domain of strategic planning; the difference was in favor of educators with diploma degree and above.

According to the employment status of school principle and school teacher the mean and the standard deviations computed for the six domains to answer the part related to the employment status, then to detect the statistical significant differences between means the independent sample $\mathrm{T}$ test was used, and the results as shown in table 4 below.

The result from table 4 above refers that there is no statistical significant differences due to the employment status in the domain of strategic planning, school learning, and Learning Climate, while there was statistical significance differences in the domains of school leadership, educational technology, and exams \& testing. The result was in favor of teacher. Finally to answer the part that related to the years of experience of both school principle and school teacher, the mean and the standard deviations was computed for the six domains according to the years of experience, then to detect the statistical significant differences between means the independent sample $\mathrm{T}$ test was used, and the results as shown in table 5 below.

The result from table 5 above shows that there is no significance difference due to years of experience in all of the domains

\section{Conclusion and Recommendation}

The results of the study indicated that the implementation of educational technology came in the first place its probably due to the concern the Ministry of Education for the implementation of Educational Commerce and taking advantage of this technology to access the world of information and knowledge that continually changing. This agrees with the study for Akababa-Altun (2001) investigated the attitudes of 124 Turkish elementary school principals toward technology use. He found that principals had positive attitudes toward technology. He found that while those principals showed hesitation to the use technology in their daily work; 69 percent of them indicated that they use computers in their schools; only 27 percent indicated that they use computers outside schools. Also agree with the study of Derar Serhan (2007), the purpose of this study was to investigate the willingness of school principals to advocate and support the use of technology in their schools. Results of this study revealed that principals had positive attitudes toward the use of technology in teaching. Results also showed that not only were the principals willing to support the use of technology in their schools but that they were also willing to improve their knowledge, abilities and skills to facilitate the integration of the technology into the curriculum. The results also indicate that the level of utilizing strategies planning came to a medium degree in the last rank of the six dimensions this may be due to the fact that the practice of school administrators for planning still depends on improvisation and randomization sometimes or situational management. This agrees with al-ajamee (2008) that the educational institution will not face any plunge in the future because of the leadership but the plunge will be because of the refusal of the school administrators to implement and utilize strategies planning. The results of the study also indicate that there was significant differences attributable to the gender, it was in favor of male school administrators in the domain of school learning and school climate it's probably due to our society's reflection still male dominated (deliberation) traditionally the stereotype in our society's that the family pay big attention for male individual more than the female,. Gender equity is a broad social issue that can be profoundly influenced in the field of education. The goal of education is to provide opportunities to gain knowledge, skills and attitudes that prepare young people for the adult world. To accomplish this purpose, schools should follow goals and objectives which communicate a philosophy of equality for all. The climate of equitable learning can help all students become aware of the careers available to them and help prepare them for changing roles at home and in the work place. Biased opportunities and differential expectations resulting from sex bias and role stereotyping can cause students to lose the freedom of career choice and limit their ability to learn and to succeed. Furthermore, sex bias and stereotyping may negatively affect a state's economy and quality of life by not utilizing the skills and talents of all students most effectively (Wisconsin Department of Public Instruction, 1990). A study of sources affecting sex equity of vocational teachers is critical to provide means of change that will lead to more productive programs. The local school principal typically has the greatest impact on school level employment decisions because the school principal is the chief executive officer of the basic unit in the school system. According to Linn (1988), the administrators are the key personnel to actually achieve and maintain sex equity in schools. They can best recognize appropriate strategies to overcome barriers to implementation. Therefore, principals' attitudes would logically be a key factor in elimination 
of sex bias in vocational teaching areas. Also the results of the study indicated that there was no statistically significant differences attributable to the variable of educational credentials for all domains except the strategic planning domain where the differences came in favor of whom their educational credentials was diploma and above, it's probably due that this category was effected with the obtained information as a result of their studies or their contact with other groups more knowledge and information. whereas result refers that there is no statistical significant differences due to the employment status in the domain of strategic planning, school learning, and learning climate, while there was statistical significance differences in the domains of school leadership, educational technology, and exams \& testing, in favor of teacher. Xin Ma; and MacMillan, (1999). Study was used to examine how teacher professional satisfaction is related to background characteristics and workplace conditions measured through teaching competence, administration control, and organizational culture. Results show that female teachers were more satisfied with their professional role as a teacher than were their male counterparts. Teachers who stayed in the profession longer were less satisfied with their professional role. Workplace conditions positively affected teacher satisfaction; administration control was the most important, followed by teaching competence and organizational culture. Significant interactions between teacher background characteristics and workplace conditions occurred. The gender gap in professional satisfaction grew with increased teaching competence. Darling (1992) indicated that administrative positions within the educational system tend to be held by men. Finally the results of the study indicated that there was no statistically significant difference due to the years experience variable in all dimensions, it's possibly due to the fact that all of these groups were exposed to in-service training and they have common vision for educational development and improvement. Further research in this direction and more hands-on training for school principals are needed. In general Pfalzer (1990) reported that the under-representation of women in administration is not due to a lack of ambition for these positions. Instead, variables which suggested explanations for the under-representation included males having advanced degrees, males having more years of experience and males having greater administrative course work. Margaret and Victoria (1990) Study seventy-three teachers participated in this study which examined teachers' knowledge of developmentally appropriate practice as related to: education /academic degree; supervised practical experience, and years of employment in education. The results indicated that knowledge of appropriate practice is dependent upon academic training in and supervised practical experiences; length of employment in education situations does not have a significant effect on teachers' knowledge of appropriate practice. Future studies should be conducted on teacher training workshops are recommended to assess the principals' abilities for the effectiveness of school performance by both school principal and school teachers.

\section{References}

Abdullah, Ibrahim. (2002). Increases the productive efficacy of the School Institution. Beirut, Lebanon, publications company for distribution and publication.

Abu Mallouh, Mohammed. (2003). Total quality and educational reform. Journal Educational Visions - Issue 10. Qattan Centre for Educational Research and Development - Ramallah - Palestine.

Al-ajamee, Husain. (2008). Administration and educational planning theory and practices. Dar al-massira, Amman Jordan.

Al-Ghafri, Saleh. (2004) The Degree of Applying Total Quality Management in basic schools at the Sultanate of Oman As perceived by Principals, Master thesis Al-yarmook University.

Alliance for Excellent Education. (2007). High school teaching for the twenty-first century: Preparing students for college. Washington, DC.

Akababa-Altun, S. (2001, September). Elementary school principals' attitude towards technology and their computer experience. Paper presented at the World Congress on Computational Intelligence (WCCI) Triennial World Conference, Madrid, Spain. (ERIC Document Reproduction Service No. ED 477 708).

Bulach, Malone \& Castleman. (1995). An investigation of variables related to student achievement. Mid-Western Educational Researcher, 8(2), 23-29

Charlton Tony, Kevin Jones, Margaret Ogilvie. (1989). Primary, Secondary and Special School Teachers' Perceptions of the Qualities of Good Schools Journal of Educational Studies.

Cochran-Smith, M. (2004a). Taking Stock in 2004: Teacher Education in Dangerous Times. Journal of Teacher Education, vol. 55, pp. $3-7$

Clotfelter, C. T, Ladd, and J. Vigdor. (2007). Teacher credentials and student achievement in high school: A cross-subject analysis with fixed effects. Washington, DC: Urban Institute. 
Corbett, C., and Huebner T. (2008). Rethinking high school: Preparing students for success in college, career, and life. San Francisco.

Darling-Hammond, L. (2007). Recognizing and enhancing teacher effectiveness: A policymaker's guide. In L. Darling-Hammond and C. D. Prince (eds.), Strengthening teacher quality in high-need schools—policy and practice. Washington, DC: The Council of Chief State School Officers.

Darling, J. (1992). The best man for the job: women teachers, promotion, and the strathclyde research. Scottish Educational Review, 24(1), 45-56

Derar Serhan. (2007). The Turkish Online Journal of Educational Technology - TOJET ISSN: 1303-6521 volume 6 Issue 2 Article 5

Elias, Waheb. (2007). The concepts of Total Quality in Education, a working paper submitted to the twelfth meeting of the educational supervision, held in Tabuk, Saudi Arabia Kingdom under the titled Educational Leadership in the light of contemporary changes.

Goldhaber, D. (2006). Everyone's doing it, but what does teacher testing tell us about teacher effectiveness? Washington, DC: Urban Institute.

Goldhaber, D. and. Brewer D. (2000). Does teacher certification matter? High school teacher certification status and student achievement. Educational Evaluation and Policy Analysis 22 (2).

Gordon, R. Kane, and. Staiger D. (2006). Identifying effective teachers using performance on the job. Washington, DC: The Brookings Institution Teacher Quality.

Hanushek, E, Kain J, and Rivkin S. (2005). Teachers, schools, and academic achievement. Econometrica 73 (2). Pages 417-458

Jepsen, C. and S. Rivkin, 2002. "What is the Tradeoff Between Smaller Classes and Teacher Quality?" NBER Working Paper No. W9205.

Kane Thomas. and Staiger Douglas, (2006). "Identifying Effective Teachers Using Performance on the Job" Hamilton Project Discussion Paper, Published by the Brookings Institution.

Khatib Ahmad, Khatib Rdah (2004). Applications of Total Quality Management in educational (book) study commissioned by the Arab Bureau of Education for the Gulf States.

Kazman, J. G. (2000). Measurement for results implementing performance measure in local government participant's handbook, Washington D. C: International City Management Association.

Linn, L. (1988). Sex equity in education. Springfield, Illinois: Charles C. Thomas Publisher.

Manasir, Ali Fallah. (1994) Total Quality Management in the Electricity Authority of Jordan, Master Thesis, Jordan University.

Margaret Hardy Snider and Victoria R. Fu (1990) Early Childhood Research Quarterly (5) 1, Pages 69-78

Pfalzer, J. (1990). The administrative aspirations and the dominance-submissiveness personality trait of female teachers in Wayne County, Michigan. Dissertation Abstracts International, 52(04), 1161. (University Microfilms No. 9118918).

Reynolds, D. (1994) The Effective School: A Revised version of an Inaugural Lecture. University of Newcastle upon Tyne.

Sanders, W., \& Rivers, J. (1996). Cumulative and residual effects of teachers on future student academic achievement (Research progress report). In University of Tennessee Value-Added Assessment Center, Knoxville, TN. (Retrieved March 28, 2001), [Online] Available: http://mdk12.org/practices/ensure/tva/tva_2.html.

Steiner, D. and Rozen, S. (2003) Preparing Teachers: Are American Schools of Education Up to The Task? [Online] Available: www.aei.org/docLib/20031023_steiner.pdf

Tellez, K. (2003). Three themes on standards in teacher education: Legislative expediency, the role of external review, and test bias in the assessment of pedagogical knowledge, Teacher Education Quarterly, [Online] Available: http://www.findarticles.com/p/articles/mi_qa3960/is_200301/ai_n9175000

Wisconsin Department of Public Instruction (1990). Wisconsin model for sex equity. Madison, Wisconsin.

Xin Ma; and Robert B. MacMillan, (1999). Influences of Workplace Conditions on Teachers' Job Satisfaction. The Journal of Educational Research, (93)1, 1999, pages 39 - 47 
Table 1. The means and std. deviations for school principal and school teacher

\begin{tabular}{|l|c|c|c|c|c|c|}
\hline & \multicolumn{3}{|c|}{ School principal } & \multicolumn{3}{c|}{ School Teacher } \\
\hline Domain & Mean & S D & Degree level & Mean & S D & Degree level \\
\hline Educational Technology & 3.94 & 1.04 & High & 4.12 & .69 & High \\
\hline Exams \& Testing & 3.86 & 0.90 & High & 4.09 & .69 & High \\
\hline Learning Climate & 3.85 & 0.96 & High & 3.82 & .87 & High \\
\hline School Leadership & 3.21 & 0.93 & High & 3.54 & .67 & High \\
\hline School Learning & 3.15 & 0.94 & Medium & 3.41 & .86 & Medium \\
\hline Strategic Planning & 2.90 & 0.99 & Medium & 3.28 & .82 & Medium \\
\hline
\end{tabular}

Table 2. The independent sample $\mathrm{T}$ test result for the gender

\begin{tabular}{|c|c|c|c|c|c|}
\hline Domain & Gender & Mean & S D & $\mathrm{t}$ & Sig. \\
\hline \multirow[t]{2}{*}{ Strategic Planning } & Male & 3.28 & 0.86 & \multirow[b]{2}{*}{0.923} & \multirow[b]{2}{*}{0.677} \\
\hline & Female & 3.18 & 0.87 & & \\
\hline \multirow[t]{2}{*}{ School Leadership } & Male & 3.50 & 0.81 & \multirow[b]{2}{*}{0.293} & \multirow[b]{2}{*}{0.319} \\
\hline & Female & 3.47 & 0.70 & & \\
\hline \multirow[t]{2}{*}{ School Learning } & Male & 3.61 & 0.78 & \multirow[b]{2}{*}{3.39} & \multirow[b]{2}{*}{0.002} \\
\hline & Female & 3.23 & 0.91 & & \\
\hline \multirow[t]{2}{*}{ Educational Technology } & Male & 4.13 & 0.75 & \multirow[b]{2}{*}{0.798} & \multirow[b]{2}{*}{0.69} \\
\hline & Female & 4.05 & 0.76 & & \\
\hline \multirow[t]{2}{*}{ Learning Climate } & Male & 4.02 & 0.75 & \multirow[b]{2}{*}{2.648} & \multirow[b]{2}{*}{0.013} \\
\hline & Female & 3.72 & 0.92 & & \\
\hline \multirow[t]{2}{*}{ Exams \& Testing } & Male & 4.06 & 0.84 & \multirow[b]{2}{*}{-0.099} & \multirow[b]{2}{*}{0.913} \\
\hline & Female & 4.07 & 0.73 & & \\
\hline
\end{tabular}

Table 3. The means \& std. deviation according to educational credentials

\begin{tabular}{|c|c|c|c|c|c|}
\hline Domain & Degree & Mean & S D & $\mathrm{t}$ & sig \\
\hline \multirow[t]{2}{*}{ Strategic Planning } & $\mathrm{BA}$ & 3.26 & 0.87 & \multirow[t]{2}{*}{1.288} & \multirow[t]{2}{*}{0.808} \\
\hline & Diploma \& up & 3.12 & 0.85 & & \\
\hline \multirow[t]{2}{*}{ School Leadership } & $\mathrm{BA}$ & 3.45 & 0.79 & \multirow[t]{2}{*}{-0.708} & \multirow[t]{2}{*}{0.031} \\
\hline & Diploma \& up & 3.52 & 0.63 & & \\
\hline \multirow[t]{2}{*}{ School Learning } & $\mathrm{BA}$ & 3.30 & 0.94 & \multirow[t]{2}{*}{-1.588} & \multirow[t]{2}{*}{0.013} \\
\hline & Diploma \& up & 3.48 & 0.75 & & \\
\hline \multirow[t]{2}{*}{ Educational Technology } & $\mathrm{BA}$ & 4.04 & 0.86 & \multirow[t]{2}{*}{-0.941} & \multirow[t]{2}{*}{0.003} \\
\hline & Diploma \& up & 4.13 & 0.51 & & \\
\hline \multirow[t]{2}{*}{ Learning Climate } & $\mathrm{BA}$ & 3.72 & 1.01 & \multirow[t]{2}{*}{-2.813} & \multirow[t]{2}{*}{0000} \\
\hline & Diploma \& up & 4.03 & 0.48 & & \\
\hline \multirow[t]{2}{*}{ Exams \& Testing } & BA & 3.95 & 0.84 & \multirow[t]{2}{*}{-3.323} & \multirow[t]{2}{*}{0.025} \\
\hline & Diploma \& up & 4.27 & 0.57 & & \\
\hline
\end{tabular}


Table 4. The means \& std deviation for employment status

\begin{tabular}{|c|c|c|c|c|c|}
\hline Domain & Position & Mean & S D & $\mathrm{t}$ & Sig. \\
\hline \multirow[t]{2}{*}{ Strategic Planning } & Principal & 2.90 & 0.99 & \multirow[t]{2}{*}{0.01} & \multirow[t]{2}{*}{0.82} \\
\hline & Teacher & 3.29 & 0.82 & & \\
\hline \multirow[t]{2}{*}{ School Leadership } & Principal & 3.21 & 0.94 & \multirow[t]{2}{*}{-2.906} & \multirow[t]{2}{*}{0.001} \\
\hline & Teacher & 3.54 & 0.68 & & \\
\hline \multirow[t]{2}{*}{ School Learning } & Principal & 3.15 & 0.95 & \multirow[t]{2}{*}{-1.921} & \multirow[t]{2}{*}{0.19} \\
\hline & Teacher & 3.42 & 0.87 & & \\
\hline \multirow{2}{*}{$\begin{array}{l}\text { Educational } \\
\text { Technology }\end{array}$} & Principal & 3.85 & 0.96 & \multirow[t]{2}{*}{-2.343} & \multirow[t]{2}{*}{0.005} \\
\hline & Teacher & 4.13 & 0.70 & & \\
\hline \multirow[t]{2}{*}{ Learning Climate } & Principal & 3.86 & 0.91 & \multirow[t]{2}{*}{0.237} & \multirow[t]{2}{*}{0.71} \\
\hline & Teacher & 3.82 & 0.87 & & \\
\hline \multirow[t]{2}{*}{ Exams \& Testing } & Principal & 3.94 & 1.05 & \multirow[t]{2}{*}{-1.295} & \multirow[t]{2}{*}{0.04} \\
\hline & Teacher & 4.09 & 0.70 & & \\
\hline
\end{tabular}

Table 5. The means \& std. deviation for of years of experience

\begin{tabular}{|c|c|c|c|c|c|}
\hline Domain & Years of Experience & Mean & S D & $\mathrm{t}$ & Sig. \\
\hline \multirow{2}{*}{ Strategic Planning } & Less than 10 & 3.06 & 0.89 & \multirow{2}{*}{0.092} & \multirow{2}{*}{0.524} \\
\hline & More than 10 & 3.05 & 0.79 & & \\
\hline \multirow{2}{*}{ School Leadership } & Less than 10 & 3.46 & 0.80 & \multirow{2}{*}{0.933} & \multirow{2}{*}{0.722} \\
\hline & More than 10 & 3.35 & 0.73 & & \\
\hline \multirow{2}{*}{ School Learning } & Less than 10 & 3.42 & 0.87 & \multirow{2}{*}{0.96} & \multirow{2}{*}{0.625} \\
\hline & More than 10 & 3.22 & 0.85 & & \\
\hline \multirow{2}{*}{ Educational Technology } & Less than 10 & 4.09 & 0.77 & \multirow{2}{*}{1.564} & \multirow{2}{*}{0.857} \\
\hline & More than 10 & 4.09 & 0.65 & & \\
\hline \multirow{2}{*}{ Learning Climate } & Less than 10 & 3.93 & 0.80 & \multirow{2}{*}{-0.059} & \multirow{2}{*}{0.868} \\
\hline & More than 10 & 3.91 & 0.76 & & \\
\hline \multirow{2}{*}{ Exams \& Testing } & Less than 10 & 4.20 & 0.73 & \multirow{2}{*}{0.109} & \multirow{2}{*}{0.878} \\
\hline & More than 10 & 4.11 & 0.68 & & \\
\hline
\end{tabular}

